\title{
Guest editorial: new horizons in organizational cognition
}

The expression "organizational cognition" (OC) has been around for quite some time now (Ilgen et al., 1994; Hodgkinson and Healey, 2008; Walsh, 1995). Applications, more than theoretical developments, gave OC a place within the management literature so that a cognitive component is found more and more often in published research. Yet, what the word "cognition" means within the context of organizations remains vague and highly dependent on theoretical assumptions (Secchi and Adamsen, 2017). On the one hand, cognition is addressed starting from more traditional organizational characteristics, with attention to, among the many, leadership (Lord and Emrich, 2001), teams and groups (Ilgen et al., 2005; Toma and Butera, 2015) and individual social responsibility (Crilly et al., 2008; Secchi, 2009). On the other hand, organization theory and behavior are addressed from the perspective of cognition, with particular emphasis to, for example, cultural ecologies (Hutchins, 2014), human interactivity (Steffensen and Pedersen, 2014) and decision-making (Bardone, 2011; Toma and Butera, 2009). The former, and more traditional, assumptions can be called representationalistwhile the latter belong to the embodied, distributed and extended cognition (EDEC) perspective. When taking a representationalist stance, researchers operate on the assumption that cognitive processes involve the mirroring of the observed in a cognitive "device." Traditionally, this has been considered to be the human brain, where observed phenomena are represented.

The EDEC perspectives take a different set of assumptions and make the issue of representation secondary, when not irrelevant. This is not the place to get involved in the debate between these two streams of research because (1) it is a relatively old one (e.g. Varela et al., 1991), and (2) it is not the central message of this editorial. All that matters here is that an EDEC stance consists in defining cognition as a system where a number of internal resources (e.g. brain, body, feelings) are mixed and interplay with external resources (e.g. artifacts, other people). Even though there has been a long tradition of EDEC perspectives in the cognitive sciences (Varela et al., 1991; Hutchins, 1995), they have not been recognized in OC until very recently. For example, Healey et al. (2018) discuss distributed cognition within a representationalist framework, and Hodgkinson (2015) has acknowledged their existence in his influential review of managerial and organizational cognition (MOC).

The two lines of reasoning about OC are still separate but, perhaps, less irreconcilable. Of course, some would keep a radical take while others would want to establish a dialogue and explore the territory around their field. This Special Issue New Horizons in Organizational Cognition has been created with the intention of drawing attention to the different aspects of cognition research applied to and concerning organizations in an attempt to understand the extent to which the two stances above communicate, diverge, merge or dialogue. The idea was that of encouraging a reflection starting from diverse theoretical perspectives, e.g. computationalism and its opposite, social identity theory, mental representationalism and its critics, sensemaking, as well as from different disciplinary traditions, even if outside organizational theory and behavior, e.g. cognitive psychology, social cognition, cognitive 
science, artificial intelligence. This would have encouraged a wide approach to OC and, at the same time, helped frame where next can the field move toward.

The Special Issue was specifically designed to attract those perspectives that serve as a bridge between existing and forthcoming OC studies. This offers a wider opening to more recent trends in OC that, given the evolution of the field, are more tied to EDEC or, as they have been otherwise labeled, e-cognition studies (Cowley and Vallee-Tourangeau, 2017). This does not mean that we (as guest editors) have worked to exclude more traditional cognitive approaches in organizational behavior (Simon, 1997; Kahneman, 2003; Gigerenzer and Brighton, 2009), but that those research studies already find a publishing "home" elsewhere; hence, they are less likely to be attracted by a forward-looking special issue.

We also wanted to use this publication as an opportunity to open organization research to those scholars who take a radical and/or critical stance on the role of cognition in organizations and of organizations (i.e. the "social") for cognitive processes. For example, the discussion of language, languaging and communication in relation to cognition in organizations has been overlooked by management scholars so far, but there is a growing interest in the cognitive literature (since Cowley, 2011). Another interesting example is that of using computational simulation (e.g. agent-based modeling) to model cognition and study emergent organizational behavior (Secchi and Neumann, 2016) and cognition (Secchi, 2021).

In other words, the aim of the Special Issue was to attract papers with new and promising theoretical perspectives that could help to boost the development of such an important area of research. This is a particularly ambitious aim, and we attempted to address it by calling for papers that build on traditional and more heterodox (cross-disciplinary) research.

Another source of inspiration for this Special Issue has been the place from where it all started. One of us co-organized and co-chaired (with Emanuele Bardone, University of Tartu) the official track "Organisational Cognition: Theories, Applications and Advancements" of the Organizational Behavior Strategic Interest Group, European Academy of Management (EURAM) annual conference, Lisbon, Portugal. The track attracted a number of papers, of which about 17 were presented at the conference. We had a few days of passionate and constructive debate where a variety of perspectives, assumptions and methodologies came together in a quite harmonious way. We all left the conference with a frame of mind that needed to be followed up. Here came the idea of the Special Issue, thought as a way to offer a platform from where that debate from the EURAM conference could continue.

The resulting Special Issue was offered primarily to participants of the conference and to a wider audience of colleagues, in the hope more were interested. As it usually happens, some colleagues already made plans for their papers, and we received only a fraction of the original 17 papers presented at the conference. In spite of these defections, we managed to attract some attention and received a total of 15 submissions. Of these, five have been accepted for publication and are featured in the current issue. The range of topics and approaches to OC is as wide as we expected it to be, with most papers presenting an attempt to draw on relatively traditional topics to then open up for some more heterodox perspectives.

In the following pages, we do not necessarily offer a summary of the papers - that can be easily found in an abstract - but have tried to indicate a few reasons why we think each one of the papers is worth reading. 
In the paper "A missing link: a distributed cognitive perspective on fit", Gayanga B. Herath presents a review of the person-environment (P-E) fit literature, a stream of research that has its typical application in recruitment and selection. The different P-E fit measures are designed to understand whether two entities - for example, a person and an organization - are compatible together. The simple idea of the article is that of asking the question "what happens to fit if cognition is considered?" The author presents the challenging perspective of an organization-cognition mechanism to study fit and argues that computational simulation research could be a game changer in this respect. Both cognition and computational simulation are new to P-E fit, and this is why we believe this paper is particularly promising.

Considering the lack of studies examining whether mental simulation can attenuate the IPE, in the paper "Mental simulation and the individual preference effect", Nicholson et al. performed two experiments to examine the effect of a mental simulation intervention in attenuating the individual preference effect (IPE) and improving decision quality in an online individual hidden profile task. One of the main takeaways from this paper is that individuals undertaking mental simulation had an improved decision quality compared to those in a control condition. Moreover, they experienced a greater reduction in confidence in the suboptimal solution. These findings open up a new and exciting line of research for the role of mental simulation in hidden profile decision tasks and can greatly benefit future studies focused on the improvement of group decision-making based on interventions with individual decision-makers.

Rasmus Gahrn-Andersen is the author of "Conceptualizing change in organizational cognition", a paper that tackles a seemingly traditional topic (i.e. change) to ask a series of fundamental questions. By expanding what he called a radical approach to organizational cognition (ROC), the author shows that even EDEC perspectives (specifically, distributed ones) fall short of explaining organizational complex adaptive and time-bound dynamics. This, in turn, highlights not only that change is an unavoidable organizational feature but that it permeates most organizational domains. Hence, a study of cognition in organizations necessitates a framework that combines micro-, macro- and (most importantly) mesodomains. Gahrn-Andersen brings this discourse to the fore with clarity and a few thoughtprovoking arguments that make the paper an interesting read.

The paper of Menezes et al. "Measuring organizational climate via psychological networks analysis" is of importance for this Special Issue and thus for several reasons. First, it introduces a new technique to the field of organizational behavior, namely the psychological networks. More specifically, it aims to address the role of psychological networks in understanding the complex relation between the underlying dimensions of organizational climate. Second, by using psychological networks, it points out the central dimensions and relations that are key for organizational climate, such as organizational commitment and its fundamental connection with the positive aspects of thriving at work. This technique allows for a broader understanding of how organizational climate variables interact than what was previously identified by the mainstream methods in organizational behavior. Third, it sheds light on the important relation between thriving at work and organizational climate, by focusing on elements of organizational climate that create a positive and supportive workplace culture, such as affiliation and support. Related to the previous point, this paper offers important perspectives for intervention. It suggests that organizations that wish to foster their organizational climate should take actions that improve employees' feelings of belonging and identification with their organization. 
The paper by Line Simonsen and Sune Vork Steffensen is titled "Enacting hybrid cognition in medical discharges." This work has many reasons deserving it to be read. One of them is definitely the application of the notion of hybrid cognition. This concept allows the authors to analyze medical doctors as they practice their profession by having the flexibility of factoring in different domains, structures, nonlocal resources and a dialogical criterion. The simple fact of providing the reader with a frame that allows for cognition can be considered "hybrid" is, per se, a reason to read this paper. The other reason is that the paper uses cognitive ethnography and applies an analytical technique by the name of cognitive event analysis. As far as our knowledge is concerned, this is the first time that a business and management journal publishes an article that features this type of highly sophisticated technique for video analysis. Not only the paper is intriguing for its conceptual backing and findings, but it may contribute to open methodological options to readers.

As the succinct overview of the papers indicates, the original aim of the Special Issue has been successfully fulfilled. In fact, each and every paper is anchored in one (or both) of the two approaches mentioned at the beginning of this editorial. At the same time, all authors have engaged in a discourse that brings those perspectives forward in directions that are original, sometimes innovative and require further exploration. In other words, by pushing the (methodological, conceptual, theoretical) boundaries of existing research forward, the papers of this Special Issue do outline a "new horizon" for organizational cognition research.

\section{References}

Bardone, E. (2011), Seeking Chances. From Biased Rationality to Distributed Cognition, Volume 13 of Cognitive Systems Monographs, Springer, New York.

Cowley, S.J. (2011), “Taking a language stance”, Ecological Psychology, Vol. 23 No. 3, pp. 185-209.

Cowley, S.J. and Vallee-Tourangeau, F. (Eds) (2017), Cognition beyond the Brain. Computation, Interactivity and Human Artifice, 2nd ed., Springer, London.

Crilly, D., Schneider, S.C. and Zollo, M. (2008), "Psychological antecedents to socially responsible behavior", European Management Review, Vol. 5 No. 3, pp. 175-190.

Gigerenzer, G. and Brighton, H. (2009), "Homo heuristicus: why biased minds make better inferences", Topics in Cognitive Science, Vol. 1, pp. 107-143.

Healey, M.P., Hodgkinson, G.P. and Massaro, S. (2018), "Can brains manage? The brain, emotion, and cognition in organizations", Individual, Relational, and Contextual Dynamics of Emotions, pp. 27-58.

Hodgkinson, G.P. (2015), "Managerial and organizational cognition", in Wright, J.D. (Ed.), International Encyclopedia of the Social and Behavioral Sciences, 2nd ed., Elsevier, Oxford, pp. 479-483.

Hodgkinson, G.P. and Healey, M.P. (2008), "Cognition in organizations", Annual Review of Psychology, Vol. 59, pp. 387-417.

Hutchins, E. (1995), Cognition in the Wild, MIT Press, Cambridge, MA. 
Hutchins, E. (2014), “The cultural ecosystem of human cognition”, Philosophical Psychology, Vol. 27 No. 1, pp. 34-49.

Ilgen, D.R., Major, D.A. and Spencer, L. (1994), “The cognitive revolution in organizational behavior", in Greenberg, J. (Ed.), Organizational Behavior: The State of the Science, Lawrence Erlbaum, Mahwah, NJ, pp. 1-22.

Ilgen, D.R., Hollenbeck, J.R., Johnson, M. and Jundt, D. (2005), “Teams in organizations: from input-process-output models to IMOI models", Annual Review of Psychology, Vol. 56, pp. 517-543.

Kahneman, D. (2003), "A perspective of judgement and choice. Mapping bounded rationality”, American Psychologist, Vol. 58 No. 9, pp. 697-721.

Lord, R.G. and Emrich, C.G. (2001), "Thinking outside the box by looking inside the box: extending the cognitive revolution in leadership research", The Leadership Quarterly, Vol. 11 No. 4, pp. 551-579.

Secchi, D. (2009), "The cognitive side of social responsibility", Journal of Business Ethics, Vol. 88No. 3, pp. 565-581.

Secchi, D. (2021), Computational Organizational Cognition: A Study on Thinking and Action in Organizations, Emerald, Bingley.

Secchi, D. and Adamsen, B. (2017), "Organizational cognition: a critical perspective on the theory in use", in Cowley, S.J. and Vallee-Tourangeau, F. (Eds), Cognition beyond the Brain: Computation, Interactivity and Human Artifice, 2nd ed., Springer, Heidelberg, pp. 305-331.

Secchi, D. and Neumann, M. (Eds) (2016), Agent-Based Simulation of Organizational Behavior. New Frontiers of Social Science Research, Springer, New York.

Simon, H.A. (1997), Administrative Behavior, 4th ed., The Free Press, New York.

Steffensen, S. and Pedersen, S.B. (2014), "Temporal dynamics in human interaction", Cybernetics and Human Knowing, Vol. 21 Nos 1-2, pp. 80-97.

Toma, C. and Butera, F. (2009), "Hidden profiles and concealed Information: strategic information sharing in group decision making", Personality and Social Psychology Bulletin, Vol. 35, pp. 793-806.

Toma, C. and Butera, F. (2015), "Cooperation versus competition effects on information sharing and use in group decision-making”, Social and Personality Psychology Compass, Vol. 9, pp. 455-467.

Varela, F.J., Thompson, E. and Rosch, E. (1991), The Embodied Mind: Cognitive Science and Human Experience, MIT Press, Cambridge, MA.

Walsh, J.P. (1995), “Managerial and organizational cognition: notes from a trip down memory lane”, Organization Science, Vol. 6 No. 3, pp. 280-321. 


\section{Further reading}

Michel, A.A. (2007), “A distributed cognition perspective on newcomers' change processes: the management of cognitive uncertainty in two investment banks", Administrative Science Quarterly, Vol. 52 No. 4, pp. 507-557.

Secchi, D. and Bardone, E. (2009), "Super-docility in organizations. An evolutionary model", International Journal of Organization Theory and Behavior, Vol. 12 No. 3, pp. 339379.

Secchi, D. and Cowley, S.J. (2018), "Modeling organizational cognition: the case of impact factor", Journal of Articial Societies and Social Simulation, Vol. 21 No. 1, p. 13. 